\title{
Cultural Trauma, Hawaiian Spirituality, and Contemporary Health Status
}

\author{
Bud Pomaika'i Cook, Kelley Withy, Lucia Tarallo-Jensen \\ University of Hawai'i, Manoa, John A. Burns School of Medicine
}

\begin{abstract}
This article postulates a causative relationship between history and health status for the native people of the Hawaiian archipelago. In the last 225-years the native people of Hawai'i have undergone a series of striking changes in the expression of their culture and health status. The relationship of historical, social, and health status changes can now be studied to determine possible effects on health arising from cultural transformation. Changes the native culture experienced in the 18th and 19th centuries, especially highlighting modifications in local spirituality and gender roles, are recounted. Key incidents of dramatic and sudden cultural change reveal traumatological mechanisms sufficient in size that they may account for health disparities faced by Hawaiians today. For Hawaiians, these incidents of cultural trauma are postulated to have achieved a level of potency such that they may account for a significant factor effecting the health status of post-modern individuals and communities.
\end{abstract}

(C) 2003 Californian Journal of Health Promotion. All rights reserved.

Keywords: Culture, Trauma, Health, Hawaiian

\section{". . . the reproduction of Hawaiian society requires the reproduction of the concept of man on which the society is based." Valerio Valeri (1985)}

\section{Introduction}

Throughout history, the island archipelago of Hawai'i has been a crossroads for people traveling or migrating across the Pacific. Some of these people arrived on the shores quite by accident, such as seafarers blown off course by storms, other voyagers came with political or social agendas to impose on others. Every group that has come to the lands of Hawai'i has brought change. Depending on the social or cultural agenda of the in-migrating groups, these changes were either fairly simple to integrate, or quite dramatic in the degree of adaptation forced upon the resident populations. The degree of environmental and social alterations required of the Hawaiian population during the 18th, 19th and 20th centuries may well have caused significant personal, and communal, cultural trauma that has lasting effects today.

The Maoli people, sometimes referred to as Kanaka Maoli, are the indigenous people of the
Pacific region who occupy the islands of Polynesia. Today the Maoli people (the native population of what is now called Hawaii) exhibit some of the most devastating health statistics and social indicators in the United States. Their poor health status may be attributed, in part, to the cultural changes required of the Maoli people over the last 225 years.

The impact of in-migrating cultures arriving in the traditional lands of the Maoli people has required from them a marked degree of change and adaptation. These profound shifts in culture have produced a condition of long-term psychosocial cultural trauma similar to that experienced by other colonialized indigenous peoples (Salzman, 2001). While it has been popular to focus on changes occurring in Hawai'i since 1778 and the arrival of Capt. James Cook, or the arrival of Christian missionaries in the 19th century, some of the conditions allowing for the intensity of cultural 
reformation occurring in the last 225 years were likely exacerbated by internal cultural conditions established by the Maoli people before the arrival of European explorers.

Social and gender roles have always been given specific attention in Maoli culture; a fuller understanding of these changing roles highlights the social confusion felt by many modern Maoli people as they struggle to identify their guiding values. Elements of spirituality were integrally related to social and gender roles in the Maoli society have now been changed. "Cultural wounding" is a term used to describe incidents where a persons' or community's culture is targeted as a source for ridicule or discrimination. Such wounding may well be related to the present day health status of the Maoli people, if so, plans for cultural healing may be appropriately developed.

\section{Song of Origin for the Dual Polarity Nā Mele Kinohi o Loina Wāhine a me \\ Loina Kāne}

Contrary to what has been assumed regarding gender separation in pre-contact Hawaiian society, this very specific cultural tradition has its foundation in Maoli understanding of the Dual Polarity - giving life and breath to their concept of a Divine Principle. The Maoli concept and perpetuation of gender separation was purposeful and directed. This set of social norms arose from their understanding of the principle of the Dual Polarity.

This philosophical structure is delineated in the complex genealogical text given the title of "Kumulipo" (Beckwith, 1972). This latenineteenth century text is the only complete transcript of this genre to have survived into modern time intact. It states that the spiritual world of the Ancestors was comprised of two realms: Kumulipo, male and Pō'ele, female. The text further illuminates by saying "Hānau $k a P \bar{o}$ " - "the spiritual realm of Pō gives birth to all material female and male elements." Further it also says, "'O kāne kēia o ka wahine kela," "male this, and female that." In the Maoli cosmological system the physical world is seen to mirror the source of all creativity: what is above, the same below.
When the Kanaka Maoli were the sole architects of their destiny, all that encompassed their known world - all the elements needed to weave the physical and metaphysical tapestry of life, past and present - came under the authority of the Dual Polarity. Believing themselves as having become incarnate into physical reality with spiritual consciousness intact, the Maoli people analyzed, defined and finely categorized their new physical realm. As in all systems of philosophy it was reflective of the spiritual and cosmic spaces known by them. They gave voice to the many divisions within the Loina Kanne, the male principle and Loina Wahine, female principle in their taxonomy. Forever cognizant of their concept of the Dual Polarity in both spiritual and mundane sciences, the Kanaka Maoli were taught to never veer from their given path. To leave this way of being would cause disorder and chaos, impacting not only the physical world but the spiritual one as well and would profane the realm of the human and nonhuman alike. Maintaining the order of reality was the Maoli objective for all incarnate beings.

To maintain the spiritual integrity and to perpetuate purity of spiritual origin, Maoli men and women lived separately, that is, until such time as one was needed to complete the other.

The microcosmic kauhale - village, followed divine law by displaying gender separate housing. Each community was a microworld, reflective of the understanding of natural order, was fully functional, integrating the most mundane with the most divine. Community was seen as a metaphor for the cosmology it represented.

In this very reflective approach to community, gender guidelines were never crossed in order to protect the 'Ihi Kapu - the Sacred Law, set down by the Ancestors in millennia prior. This was a system of law that followed cosmogonic guidelines. The Dual Polarity was perpetuated on earth in order to forever care for the divine kuleana, responsibility, humankind being the only specie with the duty to protect all other specie. The Maoli brought forward a way of life that was initiated to protect and perpetuate the physical and metaphysical health of all beings. 
All life - all elements within that life, all ritual and prayer, all Ancestral dogma, all the mundane and spiritual disciplines - everything relevant to body and soul was ruled by an awareness of this Maoli philosophical truth.

It was the abandonment of this primary truth that caused the spiritual fall off the indigenous people of Hawai'i in 1819. This imposed trauma, by a small ruling elite, was a significant factor leading to the physical degeneration of the indigenous population, and allowed for the infiltration of belief systems arriving with the successive waves of Westerners. After 225 years, the Hawaiian people are still trapped in the quagmire of cultural confusion. As relates to the concerns of trauma the Hawaiians will first need to relearn their unique Song of Origin, once more live within that sacred space first enlivened by their ancestors.

\section{Traditional Maoli Spiritual Beliefs}

The indigenous Maoli spirituality includes two belief structures worthy of discussion: the 'Ihi Kapu and Huikala. These are cultural structures that were central to the ancient Maoli sense of self, both individual and social. Together they helped to describe the connection of self to perfection through spirituality.

\section{'Ihi Kapu - Sacred Law}

The concept of 'Ihi Kapu, sacred law, is a term drawn from "The Science of Lua", a mid-20th century compilation of interviews with Naluahine Kaoka'opua, as translated by Henry Kekahuna. In this text, Kekahuna translates Kapu as "restrictions." However, 'Ihi Kapu, in pre-contact Maoli culture, was much more than a restriction; it was a system of consecrated law that enabled a people to live in harmony with one another, with nature, and the spiritual realm. Manifesting itself in forms of respect for the cosmos, the term was a guide to the living, aiding them in successfully managing their physical journey in this life in order to safely return in spirit to $P \bar{o}$, the realm of the ancestors. Ihi emphasizes these values as a system of consecrated law, as the most elevated. The presence of this law was what separated all Maoli -genuine and true humans, from all others, all who did not follow the $\mathrm{Ha}$-the "breath of life."

In traditional Maoli culture, an entity cannot be absolutely kapu (protected) or absolutely noa (free from restrictions). In Maoli culture, each person is kapu relative to certain circumstances, and noa relative to others. At least some part of the divine is inherent to the indigenous selfidentity held by the Maoli people and must remain kapu for the human sphere to function properly. For the Maoli people, without this divine principle, the whole human and natural system loses its fixed foundation. The term kapu brings with it an understanding of each human as "bound" to a divine prospect. This is a necessary element in surrendering oneself to the sacredness of the 'Ihi Kapu - the Sacred Law. Kapu is, therefore, the measured sign that makes socially known the status of one's 'Ihi -one's sacred nature. If one is bound by divine law through the 'Ihi Kapu, then the breakage of that divine law would necessitate, in the pre-contact Maoli world view, the conduct of a ritual of huikala, of untangling oneself. To undo oneself from the offense through mihi -repentance and purification, is vital to the healing process, is required to become pono -righteous through virtue. The mihikala protocol, of repentance of error against divine principle cannot be initiated without huikala -untangling oneself, from the sin. This ritual/therapeutic process unties what is, essentially, a psycho-spiritual entanglement that causes the divine to become mundane, the pure to become impure. Huikala, through acts of mihi, once more allows the person to elevate their earthly presence to a place where their divine self can express itself in this material world, allowing its influence to bring about conditions of health and prosperity for all.

These concepts permeated the whole of Maoli society until 1819, when the ruling class dictated a change in religious practices, an act that removed the Maoli from their consecration to the divine through principle and practice. In the 19th Century the 'Thi Kapu was replaced for the Maoli people by a Western epistemological dogma, one that did not balance the physical with the metaphysical, the celestial with the terrestrial, the divine with the mundane. 
Understanding this key social change event leads to identification of core cultural healings that must occur in the present - the need for Hawaiians to rectify their humanity, to regain an essential selfhood, for and within themselves, a self in concert with the concept of 'Ihi Kapu.

\section{Cultural and Religious Change - The Westernization of Hawai'i, 1778-1845}

If the anecdotal evidence suggesting that Westerners landed on the shores of Hawai' $i$ before the arrival of Cook in 1778 is true, then these individuals left little in the way of substantial changes on the conduct of the native society. Westernization of the islands will be marked at the beginning with the arrival of the late-18th Century European explorers. During this period, in part because of the enthusiasm of the warring chiefs for new technologies to support their causes in internal conflicts, the Maoli people took on a wholesale appropriation of Western ways. The high chiefs of that era immediately understood the importance of the foreigner's ships and their weaponry. Kamehameha Pai'ea, a Chief from Island of Hawaii, was especially adept at maximizing the use of Western advisors and war technology in the advancement of his imperialistic aims. One of the prices for obtaining these weapons was to take on the structures of material culture of the Western mindset.

As Kamehameha Pai'ea's campaign of conquest advanced, the pool of chiefs profiting from his campaigns narrowed. Material wealth began to be concentrated in the hands of fewer and fewer chiefs. Not only did the civil wars of attrition reduce the numbers of wealthy chiefs, Western diseases began to take their toll; the chiefs were not exempt from the ravages of diphtheria or pneumonia. The chiefs' hunger for Western weapons and other imported items caused them to take on a level of debt to foreign traders that could only be expiated by further expansion of Western commercial ventures based in Hawai'i. Supporting whaling stations, sandalwood trade, the provisioning of ships, and land exchanges were ways the chiefs paid for their purchases from Western merchants.
Along with this change in commercial culture came a corresponding shift in the persons that provided counsel to the ruling chiefs. Kamehameha Pai'ea took on John Young and Isaac Davis as early advisors to help him understand the deployment of Western weapons and naval assets. John Young eventually rose to the position of Ali'i nui, senior advisor to the ruling chief, and finally Governor of the island of Hawai'i. Other chiefs, in their resistance to the incursions of Kamehameha Pai'ea, tried to form alliances with Westerners, but none were as successful as the ruler from the island of Hawai'i. Once his campaign of wars was finally finished Westerners were inextricably ensconced in key military and political advisory positions and the desire for western good was irreversibly integrated into Maoli society.

During this same period a small faction of indigenous ruling individuals made large changes in the basis for all political and, therefore, religious, policy in the island chain. Specifically, in this instance, a small percentage of ali'i, chiefly class individuals, connected primarily with Hawai'i and Maui families used their influence to make changes in the normative social order. They sought to digest the power of the foreigner; concluding, that if all was equal, then they should have the same franchise to earthly power; if not by divine right, then by divine might. When this challenge to the accepted Maoli order came to fullness, these few ali'i foisted a wave of massive cultural change on the greater population. Their acceptance of another God, and its supporting religious dogma, was taken on to justify a change, in part, that made them virtual lords over the entire chain.

Traditionally, on the death of a high chief, like Kamehameha Pai'ea, all lands would be redistributed to those in favor with the ascending chief, a practice that often led to conflict among those seeking privilege and wealth. In precontact Hawai'i, material power was also established through coherence with sacred law. It can be interpreted that Kamehameha Pia'ea's successors understood that continuance of the traditional religion would potentially take from them the material land holdings they so desired. This was an enigma could have motivated the 
succeeding rulers to proclaim such extreme changes for the people of the lands. These chiefs did not want to automatically give up the lands they had taken through conquest.

This change process accelerated in 1819, when an edict from the regent, and former Queen of Kamehameha Pai'ea, Ka'ahumanu announced a ban on all traditional spiritual practices. Some ten months later American/Christian missionaries arrived in Hawai'i. Due to the abrogation of the indigenous religious system some 10 months earlier, a conspicuous cultural vacuum was in place. A society that had evolved for millennia in concert with its spiritual system of religious practices now no longer had a religion. In finding the Christian God after overthrowing their traditional ones, these rulers created the justification for the change in cultural practice they needed to consolidate their economic and political position. By acceding to the power of this new God and his edicts, they portrayed to the masses that they were conducting themselves in a proper manner. They used the new spiritual system to justify their personal superiority and the changes in social custom that they endorsed. Unfortunately for the populace, especially for those who do not read, the adoption of another's religious beliefs came after loosing much of their traditional social franchise.

Now it can possibly be understood how the presence of Calvinist missionaries from New England came to have such a powerful impact on the social and cultural ways of Hawaiian men and women - the necessary precursor of divesting the natives of their heathen ways had already taken place before they landed. Calvinism is founded on three important and basic principles (Bowker, 1997), the first two of which resonated with the Maoli vision of creation; however, it is the third of these that was the gateway through which flowed a crashing blow to the Maoli image of self:

1. Supremacy of scripture as the sole rule of faith and practice.

The Maoli people believed in their religious traditions as passed down through a rigid and precise oral tradition of transmission. These oral traditions were watched over by a form of rabbinical college - Hale Naua, founded by the Hawai'i Island chief Ha'ao in the 11 th century.

2. An authority confirmed by the inward witness of the Holy Spirit.

The Maoli affirmed the veracity of this inward witness by noting its equivalency with their Wailua -the Soul Cluster: the 'Uhane -the conscious soul that speaks; the 'Unihipili -the subconscious soul that clings; and, the 'Aumakua - the superconscious parent that hovers. The Wailua was affirmed by the results it brought into the world. For example, if a leader was truly righteous in their vision of the divine will, their acts would reflect this truth.

3. Men and women were inherently sinful, lost in iniquity, and could only be delivered by the Bible's message.

The Maoli epistemology has no concept akin to the idea of "original sin." However, due to the Maoli belief in the power of literature as a way the divine is made manifest in this world, the literal presence of the Bible was a powerful attractant to those Hawaiians who sought the comfort and protection of this new God.

It took some time before the edict of Ka'ahumanu completely brought down the Maoli religious structure spreading throughout the islands. Even then, it was some time more before the "people" heard and understood the word of the Calvinists. The imported dogma was first embraced by the rulers which they then promoted by their direct involvement in teaching the new gospel. The rulers' purposes in having the new religion taught was, in part, to sanctify their political position and then provide the populace with a philosophical replacement for the spiritual hole left when the older Maoli values were removed.

Teaching the new religion was closely tied with promotion of the Western approach to pedagogy. 
Because of the importance placed on literacy in Maoli values, learning to read the new Paipala Bible, was taken on with great fervor. Learning to read the new religious text, according to Calvinist beliefs, also afforded Hawaiians a way to expiate actions that took them out of accord with universal order, thereby solidifying the place of the imported religious structure.

The introduced Christian dogma, with its implication that Maoli society was, and always had been, sinful, was a profound source cultural wounding during the Westernization period of Maoli history in Hawai'i. The Maoli believed that sound was spirit made manifest. Here was sound made even more vivid through printing technology. Once laid out, no mistakes could be made; the word of the Divine was immutable, and available for all to see. That this one document was the person's only way out of being Hewa -defiled, was a powerful tool the immigrant missionaries could wield in their desire to bring change into the island kingdom.

Finally, before the arrival of the European explorers and the following commercial fleets, the island archipelago did not have a single, collective name, an appellation that identified the inhabited islands as a single nation. Poetically referred to in the native language as $\mathrm{Ka}$ Pae 'Aina -the cluster of islands, the island chain did not have a single geographic, or nationalistic, name. The peoples of these islands did not call themselves "Hawaiians." However, with the loss of the Maoli philosophical and social system, the term Kanaka Maoli not longer substantiated the identity of the indigenous people of the archipelago. The Maoli people had now become Hawaiians.

All of these factors, some coming from within the Maoli people, and others arriving in the complements of ships arriving on these shores, contributed to a traumatic process of change for the Maoli. Whether it was the structure of social classes, or the cultural roles afforded to men and women, all of the normative social roles existing in pre-contact Hawai'i were overturned or questioned at some point in the course of this historical period.
The Americanization of Hawai'i, 1845-2002

An informative distinction for understanding the impacts of the social and cultural changes seen in Hawai' $i$ in the 19th century is to envision the specific influence of American, versus Anglican, culture in shaping the present day cultural circumstance of these islands.

In part, the Americanization of Hawai' $i$ began in the early 1800's when whaling ships from New England made Hawai' $i$ one of their most important centers of global operations. In addition, the fur trade between the west coast of the United States and Asian markets, and the need for food to support both the 1849 Gold Rush in California and the Federal Army during the Civil War, made substantial impact on the types of vocations promoted within the resident population of the islands. These American market influences, along with massive declines in the native population (Lindsey, 1995), eventually required the importation of several waves of agricultural laborers to work for an increasing number of American plantation owners.

One of the most important effects of the American influence was to encourage the Hawaiian aristocracy to move the government away from its monarchal form towards a constitutional monarchy. By the end of the century the government would undergo such a radical shift in form that it would become a democratic republic founded under the auspices of forces dominated by American immigrants to the kingdom. American economic interests, located either here in the islands, or supported by private or public funds emanating from the United States, did not favor the concept of showing support for a class of ruling elite. Americans arriving in these islands were only some 30 years removed from a war with England, a war that sought to bring the United States back under the rule of the British monarchy. And while these American immigrants did sometimes become citizens of the Kingdom of Hawai'i, they gave no appearance of lost loyalty to their mother culture or its approach to governance, and they fully supported its colonial aims in the Pacific. 
These change factors, some coming from within the Maoli community and others arriving in the complements of immigrants, contributed to a traumatic process of change for the Maoli. Whether it was the structure of social classes, or the cultural roles afforded to men and women, all of the normative social roles existing in precontact Hawaii were overturned or questioned at some point in the course of this historical period.

The Americanization of the Hawaiian territory picked up additional steam when American incursions into the Pacific took on a greater importance in that nation's foreign policy decisions (Ali, 1998). While the Spanish American War in 1898 lasted only some four months, America's colonial interests in the Pacific did not wane, but actually increased. Little attention is given to a war of liberation the Filipino people prosecuted from 1898 to 1903, a war to rid themselves of American incursions into their lands. Even at the end of WWII, America continued to expand its territorial interests in the region by taking under protectorate status a number of small island nations. In all these activities, American interests never overlooked the logistical and tactical importance of Hawai' $i$ to their expansionist policies in the region. With the onset of the Cold War, Hawaii's military importance to the United States was given a long-term boost with its presence as a base of operations against feared communist incursions into the region.

After World War II, the economic importance of agriculture was gradually replaced by tourism. Tourism in Hawai'i, an industry where the image of the compliant, ever willing to serve Hawaiian, is central in most marketing campaigns. To a large degree, the current impression the world population has of Hawaiian values is almost a wholly manufactured image. That which is known as Hawaiian in the visitor industry is mostly a reinterpretation of native Maoli values commingled with undifferentiated Western commercial values. At this point in history, the native people of these islands may be as far removed from traditional Maoli cultural values as they have ever been in the last 225 years.
Japanese-Americans from Hawai'i who had fought for the U.S. in Europe, now had a direct experience of their political franchise being negated, an experience common to Hawaiians after 1893. These veterans and their families were adamant that the territory should become a permanent part of the United States, and with their leadership of the state Democratic Party, in 1959, Hawai'i became a member of the Union.

\section{Shifts in Social and Gender Roles}

In considering the effects of colonialism in Hawai'i, it is illustrative asked how men's and women's social and cultural roles changed in response to historical events. Men and women's cultural roles underwent a corresponding shift in orientation and substance. From the banning of the indigenous religion in 1819 , the traditional regulatory balance between the sacred male and female principles was disrupted. Because the fundamental Maoli basis for all law was founded in a reverence for Ancestors, these alterations in social and gender states often manifested themselves as forms of social and spiritual damage. Respect for the roles of male and female Ancestors specifically, and equally, were set aside. Ritual and ceremony was done away with; only the barest minimum of court protocol remained. However, oblige to the ali'i, the ruling chiefs, was maintained.

With the loss of the 'Ihi Kapu women and men no longer had to live in separate housing. They no longer had to give devotion to their male and female ancestors. They no longer had to eat what were, essentially, kosher, food items designated to the preservation of their spiritual gender integrity. Men and women no longer ate in segregated settings. Vocations that were designated to be the work traditionally performed by men or women became interchanged and their original gender designations were lost. Men started making feather leis. Women could be found paddling canoe. Men began to attend women in the birthing of children. Women started cooking. At this time an artistic confusion began and men begin to perform women's dances, while women performed the dances previously segregated for their men. Women officiated over male rituals and men were removed from the Hale o Papa 
ritual of rebirth to normalcy upon returning from war. Working roles shifted and women started working in the kalo fields while men started to pick 'opihi (limpets). Eventually the traditions that served to protect community safety and traditional hygienic guidelines were abandoned. Men, women, children, and sometimes livestock occupied a single grass hut. The social organization coming from an annual calendar of ritual observances was set aside; holy days, all daily, monthly, and annual observations, were dissolved. While some of these functional changes may have become inevitable due to the massive die off of Hawaiians in the post-contact period, it must be noted that many gender role changes were ushered in by the removal of traditional Maoli religious and social structures when the system was dismissed in 1819 .

Western styles of political egalitarianism further removed the Hawaiian people from the separation of gender principles traditional to Maoli women and men, blending the populace into one politically homogenized, and confused, mass. In the Maoli worldview, men and women are not meant to function in the same space at all times. In this worldview it is thought that one will always seek to dominate the other for control of that space. In the Maoli sense, male and female energies are meant to unite, to come together when needed, when necessary to make the impure, divine, and, conversely, the divine, impure. For native peoples used to a distinction between classes of people, all working to do their part to bring completeness and order into the world, egalitarianism can lead to confusion of boundaries and responsibilities about who is really in charge. The Maoli people were careful to maintain order, both cosmological and temporal. Their belief was that disorder in this plane of existence created chaos in the metaphysical world. And, for the Maoli people, if chaos reigned in the metaphysical world, then the physical hasn't a chance.

These and many other changes in material and philosophical culture caused the indigenous people of the Hawaiian Islands to move away from their native image of self, and, eventually, to try to accommodate a more Western image. However, with the political and cultural renaissance of the Hawaiian culture in the 1970 's, with all of its accompanying confusion about Hawaiian-self image, some might say that this cultural accommodation was never complete. Whether Maoli, now Hawaiians, were not allowed to make this transition because of racism, or were unable due to the radical nature of this type of psychosocial/spiritual transformative shift, can only be a point of speculation at this point in time. The result was that Hawaiian women and men, became a people between cultures; comfortable in neither Western nor Maoli cultures.

\section{Historical Trauma Response and Cultural Wounding}

The preceding begins to lay a foundation for understanding a shared sense of communal and personal history shared by modern-day Hawaiians. In recent years, some cultural researchers have sought to establish a link between the history of a people with their present social circumstance. For native peoples that have been displaced in their traditional homelands a specific form of psychophysical trauma has been described, a syndrome that has discernable impacts on their health and social development. First made evident by Maria Yellow Horse Brave Heart, Ph.D. (Lakota) (Brave Heart, 2001), Historical Trauma Response (HTR) is a reaction to the violations of selfhood a classified group feels. These violations are due to being described as "different" from the norms of the incoming colonial power, in either race, culture, and/or creed. Specifically, Historical Trauma Response can be known by a spectrum of descriptors:

a. A collection of characteristics formed in reaction to trauma that a group of people have endured;

b. seriously effects the physical, emotional, mental and social well-being of individuals, families, and the entire culture;

c. its roots originate from cultural genocide;

d. is passed down through the generations, (descendants of people who have suffered genocide not only identify with the past, they also emotionally re-experience it in the present); 
e. and, symptoms include elevated suicide rates, depression, self-destructive behavior, substance abuse, identification with pain endured, fixation to trauma, somatic symptoms that don't have a "medical" reason - (anxiety, guilt, and chronic grief), (Brave Heart, 2001).

Cultural Wounding is a term used by the author Cook in his practice to indicate incidents of violation to a contemporary person's self, insults to that self that are coupled to cultural artifacts. These cultural artifacts might include one or more of the following:

- physical characteristics;

- family genealogy;

- geographical place of origin;

- traditional religious practices;

- traditional cultural practices, gender roles; and,

- distortions of the historical record.

Cultural Wounding is one of the ways a person is linked into the historical continuum of HTR. Cultural Wounding is a form of psychological/spiritual/cultural injury, and is the mechanism by which the cycle of historical trauma is made fresh in the minds and spirits of people living in the present. These wounds could serve as potential triggers for a Post Traumatic Stress Disorder (PTSD) response in the present, leading to reactions that may seem out of the ordinary when considering the actual events of an individual's life. PTSD has been associated with depression, anxiety, rigidity and impulsive behavior. PTSD has been previously been sited in relation to struggles over unresolved spiritual issues and can cause feelings of helplessness (McBride, 2002).

In support of this description is the work of Williams and Berry (1991) who have described the process of "Acculturalization Stress," how the pressures in a person's life that are attributed to the process of acculturation. Their list of symptomotology parallels that posed by Dr. Brave Heart. This stress reaction is found in immigrant populations displaced to new cultural settings, and among native children who have been removed from their indigenous culture to live in boarding schools run by religious or civic groups.

An illustration of one of the ways that cultural wounding binds a contemporary person to a cycle of HTR can be seen in the way Native Hawaiian men were divested of their primary social roles. In the late-18th and early 19th centuries the image of Maoli men's power manifested through martial prowess, and through their almost exclusive role as the purveyors of ritual.

Their role as warriors was dramatically altered by the arrival of modern war technology in 1778. The previous 100 years of internal war was quickly brought to a close when Kamehameha Pai'ea made effective use of European war technology to first defeat his enemies, then to control access to modern weapons to suppress the likelihood of new conflict. The Maoli male self-image was bound to images of spiritual prowess established through physical courage. With completion of Kamehameha Pai'ea's campaign, this formation for self-image was made obsolete, was removed, and was not replaced by another prominent, constructive spiritual/social role.

"Warriors are supposed to repel the enemy and insure the safety of the community; when this is not possible, defeat has deep psychological ramifications. Add to this the destruction of men's roles in the traditional economy, and you have men divested of meaningful cultural roles." (Duran \& Duran, 1995)

Add to this the stripping away of the indigenous spiritual structure, the cosmology which gave the Maoli a unique order and meaning to this reality, and it is possible to locate one of the potential factors for the Hawaiian males' historical cultural wounding. Removing men's function, as the warrior/protectors of their society, while also removing their ritual and cosmological basis for developing meaning, is an example of cultural wounding, one that contributes to their becoming a part of a Historical Trauma Response. 
Not only were the Maoli men removed from being the warrior/protectors for the society, they also were divested of their role as participants in a religious structure that allowed them the privilege of healing psychic wounds. Traditionally, through ritual, warriors were allowed to die a spiritual death, only to be reborn into a new world through ritual protocol in a huikala rite, a kapu removal ceremony initiated at the Hale o Papa, a shrine adjacent to the major state temple. As a perfect example of removal by death before rebirth, one of the sources for the life/death/rebirth theory is a prayer that is recited at the Hale o Papa which says:

\begin{tabular}{|c|c|}
\hline Hawaiian & English Translation \\
\hline “'E ua maika’i ae ne’i kēia pōo ko Akua Wahine. & $\begin{array}{l}\text { "This night has been favorable because of your } \\
\text { female Ancestors, }\end{array}$ \\
\hline 'A'ole e ola nā wāhine waha hewa mai ia 'oe & $\begin{array}{l}\text { Life is not granted to those before you by the } \\
\text { Female Ancestors with satiated mouths. }\end{array}$ \\
\hline E make 'ia i ko Akua Wahine." & $\begin{array}{l}\text { They (the warriors) will die at the hands of the } \\
\text { Female Ancestors." (Fornander, 1997) }\end{array}$ \\
\hline
\end{tabular}

Time and time again, through ceremonial structure, Maoli men were allowed renewal, allowed to be reborn free of the stain of war. After the abrogation of the native religious system, ritual renewal was no longer available to provide them relief from the psycho-spiritual stains acquired in this life. The removal of this values structure, one that brought order to Maoli men's lives, has not been replaced by a correspondingly powerful Western system. Without this support, the violence seen all too often in the lives of Hawaiian men, and in their families, becomes easier to understand.

\section{The Hawaiian Health Circumstance}

While there is no evidence of direct cause and effect between any of the above mentioned circumstances and the current health situation of Native Hawaiians, the fact remains that despite significant funding, equal rates of health insurance coverage and adequate health care services, Native Hawaiians have the worst health statistics in the state, and, in some cases, in the country.

Native Hawaiians have rates of type 2 diabetes four times higher than the U.S. standard population (Grandinetti et al., 1998), and mortality rates from diabetes eight times that of non-Hawaiians (Braun, 1996). Rates of heart disease mortality for Native Hawaiians are documented as one and a half times that of the total Hawai'i state population and five times that of non-Hawaiians (Johnson, Oyama, \& le Marchand, 1998). Rates from malignant neoplasms and strokes are more than three times that of Non-Hawaiians (Office of Hawaiian Affairs, 2003), and mortality rates for all cancers combined are second in the nation (to AfricanAmericans among males and to Alaska Natives among females) (Miller et al., 1996). Native Hawaiians have twice the rate of asthma as other ethnic groups, (Hawaii Department of Health, 2002). Not surprisingly, Native Hawaiians have the shortest life expectancy in the State. What is surprising, is that between 1980 and 1990, while the health statistics for the rest of the ethnic groups in the state were improving, the statistics for Native Hawaiians worsened.

This could possibly be due to risk factors, such as smoking rates being almost $50 \%$ higher than other groups and rates of obesity and overweight status being highest in the State (Hawaii Department of Health, 2002). Or perhaps this decline is due to the fact that Hawaiians have the highest rates of heavy alcohol usage, marijuana and heroine usage in the State (Hawaii Department of Health, 2002). The clearest example of the impact of the situation upon 
daily living is that $20.6 \%$ of Native Hawaiians self-rate their health as poor, compared to the next highest group, Filipinos at $12.4 \%$. Thus, health impacts quality of life and the authors believe that cultural wounding has impacted health in Hawaii to such a degree that the current funding and programs have been unable to remedy.

Support for the idea that some Hawaiians are suffering the effects of the colonial period due to cultural wounding and HTR, can also be found in a simple comparison of the health and social data describing the health status of Hawaiians with similarly disenfranchised peoples in the United States and Canada.

- Life expectancy for Aboriginal people in Canada continues to be lower than for nonAboriginal people (by about six and a half years for women and seven years for men).

- The incidence of diabetes is at least two to three times higher in the Aboriginal people than in the general Canadian population. (Royal Commission on Aboriginal People)

The authors hypothesize that cultural wounding is in part responsible for the quality of health of the Native Hawaiians. Now the question is, what can be done about it?

\section{Possible Answers}

The 'Ihi Kapu allowed for perfection of the human spirit, a spiritual bond with one's ancestors that guaranteed a certain purity and order for all of creation in the face of daily contamination. The pre-contact Maoli people lived in grass structures without Western-styled technical elements; and yet, the Maoli people created a holistic society that allowed them to perpetuate their cultural epistemology to the ultimate degree of sophistication - in medicine, physical therapy, hygiene, exercise, rearing children, psychology, and elder care. Christianity's message, as introduced in Hawaii, was that the indigenous people were inherently evil, and that all prior spirituality was demonic. Any group that is repeatedly told that their culture and beliefs are wrong, and even evil, will not find peace until they have developed a valuable identity for themselves, their beliefs and their ancestors.

Political and social polices enacted in the last 225 years, have had a profound impact on the health of the native people of Hawai'i. By removing much of the distinction separating the world of the sacred and the profane and then conducting a similar blurring of the lines of social roles distinguishing men from women, has done great harm to the sense of personal identity available to Hawaiian women and men. The concern for Hawaiians' health status must then concern itself with a number of social, cultural, and spiritual issues. For health care providers and educators it is to ask: How can we remedy the situation, and do so by improving the spiritual integration of mind, body and community for the Maoli people?

The way from here, for health care providers, for both the dominant culture, and for Hawaiians, have at least three main components:

\section{Healthcare providers must recognize the full spectrum of the need.}

In the US, only $35 \%$ of US medical schools address the cultural issues of the largest minority groups in their particular states (Flores, 2000). Ethnic groups most impacted by cultural wounding are severely underrepresented in the health workforce (Else, Palafox, \& Little, 1998). In the state of Hawai'i, at present, physicians in Hawaii of Native Hawaiian ancestry are heavily underrepresented (Kaawaloa, 2002). Therefore unless cultural concerns are introduced systematically, they will not be addressed by providers. Discussions of cultural healing are similar to discussions of spiritual beliefs. Studies have shown that spirituality is associated with improved health, longevity, coping skills and quality of life, and decreased depression and suicide (Koenig, Mcullough, \& Larson, 2000; Mueller, Plevak, \& Rummans, 2001). Furthermore, sixty three percent of Americans polled believed that physicians should discuss spiritual issues with patients (McNichol, 1996). However, evidence seems to indicate that few health care providers engage in any discussion of spiritual issues with their patients (King, Sobal, \& DeForge, 1998; Koenig, 2001). In the 
area of spirituality, the greater exposure medical students have to spiritual and religious issues in medicine, the more positive their attitudes were toward these issues (Chibnall \& Duckro, 2000).

If the health care community recognizes the importance of cultural wounding, the loss of Maoli spirituality and historical trauma and can be integrated into treatment plans with patient. Only then would there be a possibility for developing health care practices and policies sufficient to rise to the demands of the problem. To recognize that Hawaiian men and women share some aspects of this ontogeny of cultural violation, and yet that still other aspects have been unique to their evident gender, will allow health care professionals and cultural specialists to respond in appropriate ways.

\section{Develop the resources, educational initiatives.}

There is a need for activities whose aims entwine informational and healing goals. Information that has been accepted, that was formatted by the understanding of European/Male cultural norms, must be revisited to afford native worldviews to come forward. Having an opportunity to see alternatives in gender roles and responsibilities, not only brings a sense of freedom to indigenous people, but also places vigorous responsibilities before them in carrying responsibility for their personal and communal actions.

Once respect for native epistemology has been accorded the traditions of native peoples, culturally appropriate training systems for native and non-native audiences can occur. The process of education must work in harmony with the indigenous pedagogical systems of the groups being brought forward. In order to have some sense of cultural integrity, knowing must be supported by teaching. This endeavor will require much in the way of research. While there are common aspects of Hawaiian culture that can be used with men or women, there are some elements of the curriculum that must be segregated to provide each group a proper measure of respect for their unique needs and learning goals.

\section{Apply the resources.}

In order to decrease the effects of cultural trauma on this population of people, providers must first recognize the need. Next, there must be a system for cultural healing to take place. Then providers must identify patients who will benefit from cultural healing activities and provide them the essential information. Only through active use of innovative means designed to ameliorate the amplifying effects of cultural wounding and historical trauma response will any substantive change occur. Considered practice will allow for research activities to be undertaken to affirm the efficacy of means taken. A constant adjustment of methods used to assist patients must occur, and is only possible if trust is established between former cultural opponents.

\section{Cultural Healing}

The purpose of the foregoing processes are to lead to a deep cultural healing for Hawaiians, and by association, to all whom they are in community with in the present day. This is a learning model that seeks a completeness in the process of cultural healing, one that goes beyond present day ideals, a model that will help Hawaiians understand that while they need no longer be a victim, they may also pass beyond the image of themselves as survivors of colonialism. Not a victim, not a survivor, but simply a whole human being; one who keeps a memory of the past and respect for their ancestors, while being free to move with health and confidence into the future.

Education is central to the healing that Hawaiians and their communities must go through in order to enter into a new era of higher functioning. This will not be a quick process; it may take three or four generations of concerted activity before the social circumstance of Hawaiians is once more at a sufficient level of function that we can be assured of its long-term viability. Candor must be a central theme in these educational activities. In order to revive Maoli culture, a serious and thorough examination of how these indigenous values have been compromised during the colonial period must occur. Not only is the general population unclear about the reach of native 
values and practices, but modern Hawaiians are similarly confused about their native values and practices. Only through an effort deep, sincere, and culturally sensitive academic pursuit can the process of reconstruction of the Maoli character begin.

These educational endeavors must be aimed at more than information; their goal must be clearly restorative. Education that produces mere information does not have the same impact as education that seeks to elicit wisdom. To restore the presence of a clearly Maoli world view will require the acceptance of true diversity, an acknowledgement that the Western and Maoli visions of reality are co-equals that coexist in a modern world community. Their differences providing insight in ways that segregated views fail to inform.

For example, cultural healing in regards to gender roles will require some understanding and accommodation from the mainstream culture. The Maoli view of men's and women's responsibilities differs from the current political view of gender egalitarianism. While it must be understood that we do not exist in the social reality of the Hawaiian Islands in pre-contact times, in order to offer Hawaiian women and men some sense of order in their world, our society must allow for an open discussion of how Hawaiians need to adjust their expression of gender and social roles in order to feel pono correct/balanced, in their psychospiritual self. At times this treatment, in the form of education, must be all inclusive of the community, both native and non-native. At other times this protocol of treatment and education would focus on just those people in the native population, both men and women. And then at certain times, for specific purposes, treatment/education must be specific to native women only, or for native men only.

Cultural healing will not only resolve problems between Hawaiians and other immigrant populations, but will also provide an opportunity for Hawaiians to work out wounds that exist between themselves and their own history. As noted in this paper, Hawaiians have unknowingly facilitated considerable trauma amongst themselves. Cultural healing through education, and through traditional practices, will allow Hawaiians to bring internal peace to their population. For those people of mixed descent, cultural healing will reduce internal discord associated with feelings of guilt or inadequacy coming from identification with both Hawaiian and other cultural heritages. Cultural healing will be a necessary partner in training offered to health care professionals.

\section{Provider Practices}

Once a sufficient pool of validated knowledge and resources are provided, health care professionals can then utilize both in the care of their patients. Providers serving Hawaiian populations must recognize the impact of cultural wounding and historical trauma, allowing themselves to aid patients by assisting them with the process of understanding and growing from knowledge of cultural identity. Helping patients identify with an indigenous spiritual system may be the help that someone requires. The authors of this paper are not advocating that health care providers become some type of cultural/spiritual advisors, but merely that they allow for the fact that their patients might be best served by coordinating allopathic and spiritual means in the providing of healing services.

If the health care community can recognize the importance of cultural wounding and historical trauma then there is a possibility to develop health care practices and policies sufficient to rise to the demands of the problem. To recognize that Hawaiian men and women share some aspects of this ontogeny of cultural violation, and yet that still other aspects have been unique to their evident gender, will allow health care professionals and cultural specialists to respond in appropriate ways.

\footnotetext{
"'A mama, 'Ua noa."

"It is complete. It is free."
} 


\section{References}

Ali, M. (1998). Ho'ohui'aina pala ka maia: Remembering annexation 100 years ago. The Hawaiian Journal of History, 32, 141-154.

Beckwith, M. (Ed.) (1972). The Kumulipo: A Hawaiian creation chant. Honolulu, HI: University of Hawai'i Press.

Braun K. L. (1996). Native Hawaiian mortality, 1980-1990. American Journal of Public Health, 86, 888889.

Bowker, J. (Ed.) (1997). The Oxford dictionary of world religions. NY: Oxford University Press, pp. 190.

Brave Heart, M. (2001). "The circle" vol. 22, issue 1. Retrieved 2001, from http://thecirclenews.org/archives/22-1 cover.html

Chibnall, J. T., and Duckro, P. N. (2000). Does exposure to issues of spirituality predict medical students' attitudes toward spirituality in medicine? Academic Medicine, 75, 661.

Duran, E., and Duran, B. (1995). Native American postcolonial psychology. Albany, NY: State University of New York Press.

Else, I., Palafox, N., Little, D. (1998). Where are the Native Hawaiian physicians? Pacific Health Dialog, 5, 246-52.

Flores, G., Gee, D., and Astner, B. (2000). The teaching of cultural issues in U.S. and Canadian medical schools. Academic Medicine, 75, 451-455.

Fornander, A. (1974). Ancient Hawaiian religious ceremonies. In A. Fornander (Ed.), Fornander collection of Hawaiian antiquities and folklore. Honolulu, HI: Kraus Reprint, pp. 26-29.

Gathering Strength. Royal Commission on Aboriginal People. 3, 111-201. Retrieved 2001, from http://www.indigenous.bc.ca/v1/Vol1Ch3s1tos2.4.asp

Grandinetti, A., Chang, H. K., Mau, M. K., Curb, J. D., Kinney, E. K., Sagum, R., et al. (1998). Prevalence of glucose intolerance among Native Hawaiians in two rural communities. Diabetes Care, 21, 549-554.

Hawaii Department of Health. (2002). Behavioral risk factor surveillance system. Retrieved November 26, 2003, from http://www.state.hi.us/health

Johnson, D. B., Oyama, N., le Marchand, L., (1998). Papa ola lokahi Hawaiian health update: Mortality, morbidity and behavioral risks. Pacific Health Dialog, 5,297-314.

Lindsey, E. (1995). And then there were none. Video documentary.

Kaawaloa, J. N. (2002). Ethnic breakdown of physicians practicing in each county in the State of Hawaii overall, table 2, "Examining Native Hawaiian health care: Taking a closer look at Hawaiian physicians. Poster presentation, Pacific Region Indigenous Doctors Congress, Honolulu, HI.

King, D. E., Sobal, J., and DeForge, B. R. (1998). Family practice patients' experience and beliefs in faith healing. Journal of Family Practice, 27, 50-5.

Koenig, H. G., McCullough, M. E., \& Larson, D. B. (2000). Handbook of religion and health: A century of research reviewed. New York: Oxford University Press.

Koenig, H. G. (2001). Spiritual assessment in medical practice. American Family Physician, 63, 1.

McBride, J. L. (2002). Spiritual component of patients who experience psychological trauma: Family physician intervention. Journal of the American Board of Family Practice, 15(2), 168-169.

McNichol, T. (1996). The new faith in medicine. USA Weekend, April 5-7, pp. 4.

Miller, B. A., Kolonel, L. N., Berstein, L., Young, J. L., Jr., Swanson, G. M., West, D. (Eds.) (1996). Racial/ethnic patterns of cancer in the Unites States 1988-1992. Bethesda, MD. National Cancer Institute, NIH Publication 96-4104.

Mueller, P. S., Plevak, D. J., Rummans, T. A. (2001). Religious involvement, spirituality, and medicine: Implications for clinical practice. Mayo Clinic Proceedings, 76, 1225-35.

Office of Hawaiian Affairs. (2003). Home page. Retrieved November 26, 2003, from http://www.OHA.org

Salzman, M. (2001). Cultural trauma and recovery. Trauma, Violence, \& Abuse, 2, 172-191.

Williams, C., and Berry, J. (1991). Primary prevention of acculturalization stress among refugees: Application of psychological theory and practice. American Psychologist, 46, 632-41. 
Valeri, V. (1985). Kingship and sacrifice: Ritual and society in ancient Hawaii. Chicago: The University of Chicago Press.

\author{
Author Information \\ Bud Pomaika'i Cook, Ph.D.* \\ Hawai'i Pacific Basin AHEC Office \\ John A. Burns School of Medicine \\ University of Hawai'i, Manoa \\ 1266 Kamehameha Ave., Suite C \\ Hilo, HI 96720 \\ Ph. 808-935-5300 \\ E-Mail: bcook12@verizon.net \\ Kelley Withy, M.D. \\ Lucia Tarallo-Jensen \\ Hawai'i Pacific Basin AHEC Office \\ John A. Burns School of Medicine \\ University of Hawai'i, Manoa \\ * corresponding author
}

